\title{
Association between Left Ventricular Global Longitudinal Strain and Functional Capacity Measured with Six-Minutes Walk Test in Patients after Acute Myocardial Infarction.
}

\author{
Trisulo Wasyanto', ${ }^{1,2)}$, Pipiet Wulandari'1), Niniek Purwaningtyas ${ }^{1,2)}$, \\ Bhisma Murti3) \\ 1)Department of Cardiology and Vascular Medicine, \\ Faculty of Medicine, Universitas Sebelas Maret \\ 2)Dr. Moewardi General Hospital, Surakarta \\ 3)Masters Program in Public Health, Universitas Sebelas Maret
}

\begin{abstract}
Background: The ischemia resulting from critical coronary narrowing or total occlusion first affects the subendocardialmyofibers. Thus, abnormalities in longitudinal function can be detected before reductions in LVEF and reflects infarct size. The 6MWT provides information that may be a better index of the patient's ability to perform daily activities. This study was to assess the relationship between left ventricular (LV) global longitudinal strain (GLS) and functional capacity measured with 6 minute walk test (6MWT) after AMI.

Subjects and Method: This is a cross sectional study of patients with STEMI and NSTEMI, at Moewardi Hospital, Surakarta. Eligible patients underwent echocardiography global longitudinal 2D-STE that performed within 48 hour of admission and 6MWT pre- discharge or at the first follow-up visits (day 4-9). Patients were divided into 2 groups according to the LV GLS value, patients with substantial infarction (LV GLS > -13.8\%) and non-substantial infarction (LV GLS $\leq$ $13.8 \%)$.

Results: There were 50 patients with 42 STEMI and 8 NSTEMI. Compared to patients in group LV GLS $\leq-13.8 \%(n=18)$, patients in group LV GLS $>-13.8 \%(n=32)$ were more likely to be older ( 57.6 y.ovs 55 y.o), less in functional capacity $(10.17 \pm 1.3 \mathrm{ml} / \mathrm{kg} / \mathrm{min}$ vs $11.04 \pm 0.98 \mathrm{ml} / \mathrm{kg} / \mathrm{min}$; $\mathrm{p}=0.018)$ and less in 6 MWT distance $(347.97 \pm 65.49 \mathrm{~m}$ vs392.39 $\pm 49.44 \mathrm{~m} ; \mathrm{p}=0.016)$. Using ROC curves, the 6 MWT distance cutoff value of $375 \mathrm{~m}$ identified patients with LV GLS >-13.8\%, sensitivity of $72.2 \%$ and specificity $65.6 \%$, respectively with $\mathrm{AUC}=0.70$ (CI 95\%; 0.559-0.852; $\mathrm{p}=$ 0.017). However, LV GLS $>-13.8 \%$ and age $\geq 60$ y.o remained the independent predictor in a multivariate logistic regression analysis to identify $6 \mathrm{MWT}$ distance $<375 \mathrm{~m}$ in patients after AMI with GLS >-13.8\%, (OR =7.967; CI 95\%= 1.669-38.030; $\mathrm{p}=0.009)$ and age $\geq 60$ y.o, (OR=10.898; CI95\% $=2.201-53.971 ; \mathrm{p}=0.003)$.

Conclusions: In patients after AMI with substantial infarction (LV GLS >-13.8\%) had less in functional capacity. The 6 MWT distance cutoff value of $375 \mathrm{~m}$ identified patients with LV GLS >$13.8 \%$ and could be used in rehabilitation program after AMI.
\end{abstract}

Keywords: Acute Myocardial Infarction, LV Global longitudinal strain, functional capacity, 6 MWT.

\section{Correspondence:}

Trisulo Wasyanto. Department of Cardiology and Vascular Medicine, Faculty of Medicine, Masters Program in Public Health, Universitas Sebelas Maret. Jl. Ir. Sutami No. 36 A, 57126, Surakarta, Central Java.

\section{BACKGROUND}

Loss of contractile tissue abilities after acute myocardial infarction results in myocardial functional impairment in the area of the infarction depending on the extent of tissue necrosis and the decrease in 
left ventricular ejection fraction in general. Echocardiography is widely available and can be done in acute conditions so that this modality becomes the first choice in assessing risk stratification after acute myocardial infarction. Conventional echocardiography studies provide a rapid and general picture of the myocardium, but left ventricular ejection fraction is weak in detecting pathological changes early and minimal (Diao et al., 2017). In patients with acute myocardial infarction, there is damage to the myocytes. Ischemia produced by critical narrowing or occlusion of coronary arteries, first affects the sub-endocardiac myofibril because of the transmural distribution of coronary perfusion. Subendocarbum fibers become the area that first shows abnormalities of contractile function when ischemia occurs (Ersball, 2013). Therefore abnormalities in the longitudinal (longitudinal strain) function can be detected before the decrease in left ventricular ejection fraction and the level of longitudinal dysfunction of the strain indicates the magnitude of infarct (infarct size). Low left ventricular left ventricular longalvalignal (GLS) values in patients with acute myocardial infarction are associated with the extent of infarction and left ventricular ejection fraction, can predict left ventricular changes, clinical events and response to re-perfusion strategies (Gjesdal et al ., 2007).

Functional capacity is the individual's ability to perform aerobic activity as measured by maximal oxygen uptake (VO2max), which results from cardiac output (CO) and arterial and venous oxygen levels. Functional capacity is affected by cardiac output (CO), which reflects the ability for the left ventricle to pump blood and muscle ability to extract oxygen for energy production. Cardiac output (CO) is affected by the volume of stroke (SV) and heart rate. In normal adults, when the physical activity of stroke volume increases, the $\mathrm{CO}$ increases linearly in accordance with the increase in work intensity. Stroke volume can be increased by increasing contractility and ejection fraction (EF), ie the percentage of diastolic final volume that is injected during the systolic phase (Swain et al., 2014). The greater myocardial damage or decreased left ventricular function accompanying episodes of myocardial infarction acute, the lower the heart's ability to pump blood during activity or at rest, as measured by the function of the ejection fraction or cardiac output (CO). Furthermore, the greater decreased in the function of the heart pump, the lower the patient's functional capacity.

6-MWT examination is a test to measure functional capacity in target population using moderate to severe disturbance. In certain clinical situations, 6 MWT provides information about the patient's index / ability to perform daily activities rather than information on maximal oxygen uptake (Crapo et al., 2002). The clinical application of 6 MWT evolved from measuring the tolerance of training in patients with low functional capacity and high-risk groups for the maximum practice test, up to now, 6 MWT was used as a guiding prescribing activity by converting the distance obtained from the training to metabolic equivalent (MET) (Venkatesh et al., 2011).

\section{SUBJECTS AND METHOD}

Subjects were taken consecutively in patients with acute myocardial infarction with ST / IMA EST segment elevation and without ST / IMA segment elevation without EST undergoing treatment at DR. Moewardi hospital, Surakarta, Central Java and willing to do echocardiographic examination and sub-test of maximal 6 
MWT before outpatient / pre-discharge or on the first outpatient visit. Patients included in the inclusion criteria were patients with acute myocardial infarction (based on chest pain complaints, ST elevation or elevated ST elevation in ECG and elevated cardiac enzyme biomarkers), $\leq 24$ hours onset and willing to be the subject of the study. The exclusion criteria were patients with previous history of acute coronary syndrome or chronic heart failure; patients with valvular heart disease; patients with atrial fibrillation; Echocardiography examination results are not feasible for GLS analysis; patients with chronic renal failure, hepatic cirrhosis, chronic inflammatory disease or malignancy; patients with acute infection or sepsis; patients with acute stroke; patients with life-threatening arrhythmias, unstable angina after infarction; patients with untreated heart failure; patients with non cardiac abnormalities that limit the ability of motion/perform trainings such as osteoarthritis.

The global longitudinal strain is an echocardiographic examination that measures the myocardial tissue deformation / strain of the 2-dimensional image speckle tracking echocardiography (STE). The strain expresses the length change of the object relative to the initial length in percentage (\%) with the shortening written as a negative value and elongation as a positive value. Global longitudinal strains (GLS) are calculated as the mean of all segments, as a measurement of left ventricular function globally (Ersball, 2013).

Left ventricular GLS measurements were performed by using Vivid S6 Cardiovascular Ultrasound Sytem (GE Healthcare, Wisconsin, USA). GLS was examined using the automated function imaging (AFI) technique available in echocardiography machine software, based on 2-dimensional longitudinal strain imaging. Longitudinal strains are defined as physiological changes of the length of the region of interest (ROI) from the end of the diastolic phase to the end of the systolic phase. During this period, the longitudinal strain was negative because of the shortening of the ROI. GLS examination results were expressed in software such as GLPSS-Avg which reflects the overall systolic peak of each left ventricle segment (1-s2). After the GLS score was obtained, the samples are grouped into two: GLS -13.8\% and GLS> 13.8\% (Eek et al., 2010).

The 6 MWT training test is a maximal sub exercise test that measures the distance a patient can travel by walking fast on a flat surface for 6 minutes. This training test is done indoor which has a flat floor, the length of the corridor used is marked every 3 meters and marked for a turn. Patients wore comfortable clothing and footwear with continuing medicines. Patients were allowed to eat lightly before the exercise test was performed but are not allowed to do heavy activity up to 2 hours before the exercise test is carried out. The patient performede a warm-up before performing a measurement of vital signs, scoring the borg scale, ie the patient's perception of fatigue assessed on a scale of $0-10$ (o = not tired, $2=$ slightly tired, $3=$ moderate, $4=$ tired $5=$ slightly heavier, $7=$ very tired, 10 $=$ very tired (maximum)) and telemetry ECG installation. The time marker was set within 6 minutes and the patient was required to walk as far as they can but were not allowed to run. Patients were allowed to stop during the training test and then continue to walk again or stop the training test. During a live training test, the patient was informed about the time that has been spent. When 6 minutes have been reached, mileage was taken during the training test 
and documented vital signs and Borg scale perceived. The distance obtained was converted into VO2max.

The data obtained were analyzed statistically using SPSS 22.0 software. The normality test of continuous data was performed using Kolmogorov-Smirnov test. If the data is normally distributed, the average difference test is performed using an unpaired $\mathrm{T}$ test. If the data is not normally distributed, it is conducted by using Mann-Whitney test. Comparisons to categorical data were performed using chisquare test. Receiver-operating characteristic (ROC) curve analysis was performed to determine the left ventricular GLS cut point against functional capacity as measured by 6 MWT. Significant variables in univariate or biologically relevant analyzes were included in the multivariate analysis.$$
\text { RESULTS }
$$

There were 50 patients, 8 patients with IMA without EST and 42 patients with IMA EST who fulfilled inclusion and exclusion criteria, and could be examined for $6 \mathrm{MWT}$ training test. Patients with a qualified IMA EST and agreed to do fibrinolytics consisted of 36 of 42 patients and 14 of 36 who fulfilled fibrinolyticsuccess criteria. A total of 21 of 42 patients with IMA EST and 1 of 8 IMA patients without EST underwent mechanical reperfusion with stent insertion. The left ventricle GLS examination was performed on the 2nd day of admission. Intra-observer reliability analysis of left ventricular GLS measurements using Intraclass Correlation Coefficient (ICC) on 14 samples obtained ICC 0.929. The median time of the $6 \mathrm{MWT}$ training test is the $5^{\text {th }}$ day (4-9) after admission. Patients were categorized into groups with significant
}

infarct infarction (extent of infarction> $12 \%$ ), characterized by GLS> $-13.8 \%$ and a group with an insignificant infarct region characterized by GLS $<-13.8 \%$.

Groups with GLS> $-13.8 \%$ consisted of 32 patients and the GLS group $\leq-13.8 \%$ of 18 patients. The basic characteristics of patients in both groups were similarly different (demographic, sex, age and body mass index), influencing risk factors (hypertension, DM, smoking and dyslipidemia), clinical characteristics (infarct type, killip class) and therapy (medical and mechanical reperfusion), as well as the timing of the 6 MWT training test. The mean age in the GLS group of $-13.8 \%$ was 57.6 years and the GLS group $\leq-13.8 \%$ was 55.8 years with the proportion of patients with male patients equally more in both groups. The basic characteristics of both groups are shown in Table 1.

The significant differences were shown in the left ventricular ejection fraction of the group with GLS> $-13.8 \%$ lower (42.97 $\pm 7.58 \%$ ) of the GLS group $\leq-$ $13.8 \%(52.06 \pm 7.43 \%)$ with $\mathrm{p}<0.001$. If distinguished to anterior IMA type and non-anterior IMA type, the group with GLS $>-13.8 \%$ had a higher proportion of patients with anterior IMA type (56\% and $22 \%$ ) with $\mathrm{P}=0.036$.

In the different test with independent $\mathrm{T}$ test, there was a difference of mean distance at 6 MWT and functional capacity in the group with GLS $>-13.8 \%$ and GLS $\leq-$ $13.8 \%$ significantly with $\mathrm{p}<0.05$. Mileage in GLS group $>-13.8 \%$ as far as $347.97 \pm 65.49$ meters with functional capacity $10.17 \pm 1.3$ $\mathrm{ml} / \mathrm{kgBW} / \mathrm{min}$. Mileage in the GLS group $\leq-13.8 \%$ as far as $392.39 \pm 49.44$ meters with functional capacity of $11.04 \pm 0.98 \mathrm{ml}$ / kgBW / min (table 2). 
Table 1. The Characteristics of Subjects

\begin{tabular}{|c|c|c|c|}
\hline Parameter & GLS $\leq-13.8 \%(n=18)$ & GLS>-13.8\% $(n=32)$ & $\mathbf{p}$ \\
\hline \multicolumn{4}{|l|}{ Gender } \\
\hline Male, n (\%) & $15(83 \cdot 3)$ & $24(75)$ & 0.074 \\
\hline Female, n (\%) & $3(16.6)$ & $8(25)$ & \\
\hline Age & $55.83 \pm 12.45$ & $57.66 \pm 8.11$ & 0.534 \\
\hline $\begin{array}{l}\text { Body Mass Index } \\
\left(\mathrm{m} / \mathrm{kg}^{2}\right)\end{array}$ & $22.84 \pm 3.08$ & $24.6 \pm 3 \cdot 37$ & 0.074 \\
\hline Diabetes Melitus, n (\%) & $4(22.2)$ & $9(28)$ & 0.746 \\
\hline Hipertention, n (\%) & $8(44.4)$ & $16(59.4)$ & 0.382 \\
\hline Active Smoker, n (\%) & $13(72.2)$ & $18(56.2)$ & 0.366 \\
\hline Dislipidemia, n (\%) & $14(77.8)$ & $26(81.2)$ & 1.000 \\
\hline \multicolumn{4}{|l|}{ Killip Class } \\
\hline Killip I, n (\%) & $16(88.8)$ & $24(75)$ & 0.295 \\
\hline Killip II-IV, n (\%) & $2(11.1)$ & $8(25)$ & \\
\hline \multicolumn{4}{|l|}{ IMA EST Type/without } \\
\hline EST & $13(72.2)$ & $29(90.6)$ & 0.118 \\
\hline $\begin{array}{l}\text { IMA EST, n (\%) } \\
\text { IMA non EST, n (\%) }\end{array}$ & $5(27.8)$ & $3(9.4)$ & \\
\hline IMA ant type/non ant & $4(22.2)$ & $18(56.2)$ & 0.036 \\
\hline IMA anterior, n (\%) & $14(77.7)$ & $14(43.7)$ & \\
\hline \multicolumn{4}{|l|}{ IMA non anterior, $\mathrm{n}$} \\
\hline $\begin{array}{l}\text { Ejection fraction } \\
\text { (Simpson) (\%) }\end{array}$ & $52.06 \pm 7.43$ & $42.97 \pm 7.58$ & $<0.001$ \\
\hline \multicolumn{4}{|l|}{ Fibrinolitik } \\
\hline Yes, n (\%) & $13(72.2)$ & $23(71.9)$ & 1.000 \\
\hline No, n (\%) & $5(27.8)$ & $9(28.1)$ & \\
\hline \multicolumn{4}{|l|}{ PCI, n (\%) } \\
\hline Yes, n (\%) & $9(50)$ & $13(40.6)$ & 0.565 \\
\hline No, n (\%) & $9(50)$ & $19(59.4)$ & \\
\hline Distance 6 MWT (meter) & $392.39 \pm 49.44$ & $347.97 \pm 65.49$ & 0.016 \\
\hline $\mathrm{VO}_{2} \max (\mathrm{ml} / \mathrm{kgBB} / \mathrm{min})$ & $11.04 \pm 0.98$ & $10.17 \pm 1.3$ & 0.018 \\
\hline
\end{tabular}

Table 2.The comparison of mean distance at 6 MWT between GLS groups

\begin{tabular}{clcc}
\hline & n & Mean \pm SD & p \\
\hline GLS $\leq-13.8 \%$ & 18 & $392.39 \pm 49.44$ & 0.016 \\
GLS $>-13.8 \%$ & 32 & $347.97 \pm 65.49$ & \\
\hline
\end{tabular}

Table 3.The average comparison of VO2max values between GLS groups

\begin{tabular}{llcc}
\hline & n & Mean \pm SD & p \\
\hline GLS $\leq-13.8 \%$ & 18 & $11.04 \pm 0.98$ & 0.018 \\
GLS $>-13.8 \%$ & 32 & $10.17 \pm 1.3$ & \\
\hline
\end{tabular}

Mileage distance during the $6 \mathrm{MWT}$ training test indicating the group with GLS $>-13.8 \%$ was determined using the ROC curve. On the ROC curve obtained cutoff point 375 meters with a sensitivity of $72.2 \%$ and specificity of $65.6 \%$. The value of the under-the-curve (AUC) area is 0.70 (IK
95\% 0.559-0.852; $\mathrm{p}=0.017$ ). This value can be interpreted from 70 out of 100 patients after myocardial infarction tested 6 MWT which has a distance of less than 375 has an area of infarction $>12 \%$ indicated by GLS >-13.8\%. 


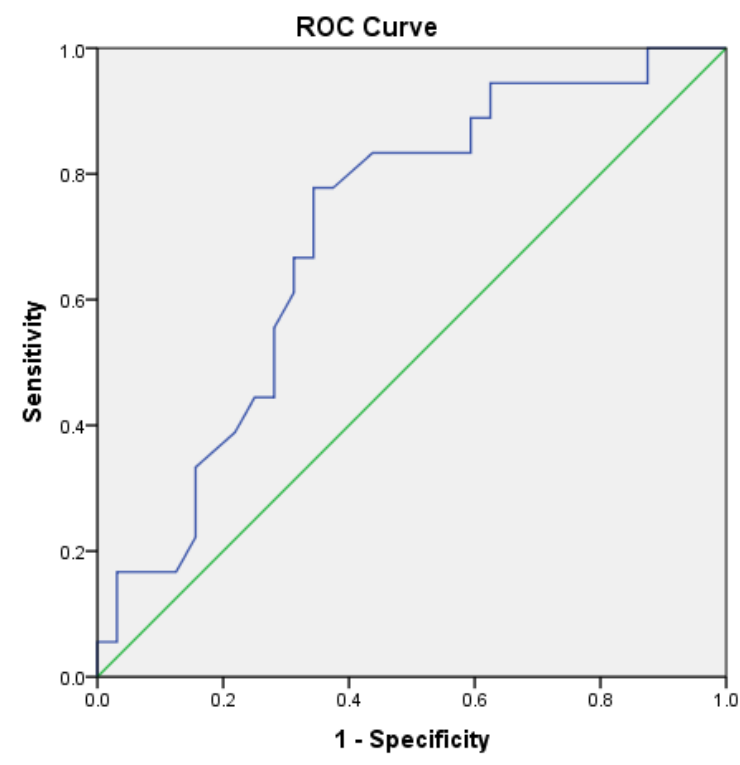

Figure1.Analysis Curve ROC GLS $>-13.8 \%$ on the distance 6MWT and cutting point 375 meters, AUC: $0,706(95 \% \mathrm{CI}=0.56$ to $0.85 ; \mathrm{p}=0.017)$

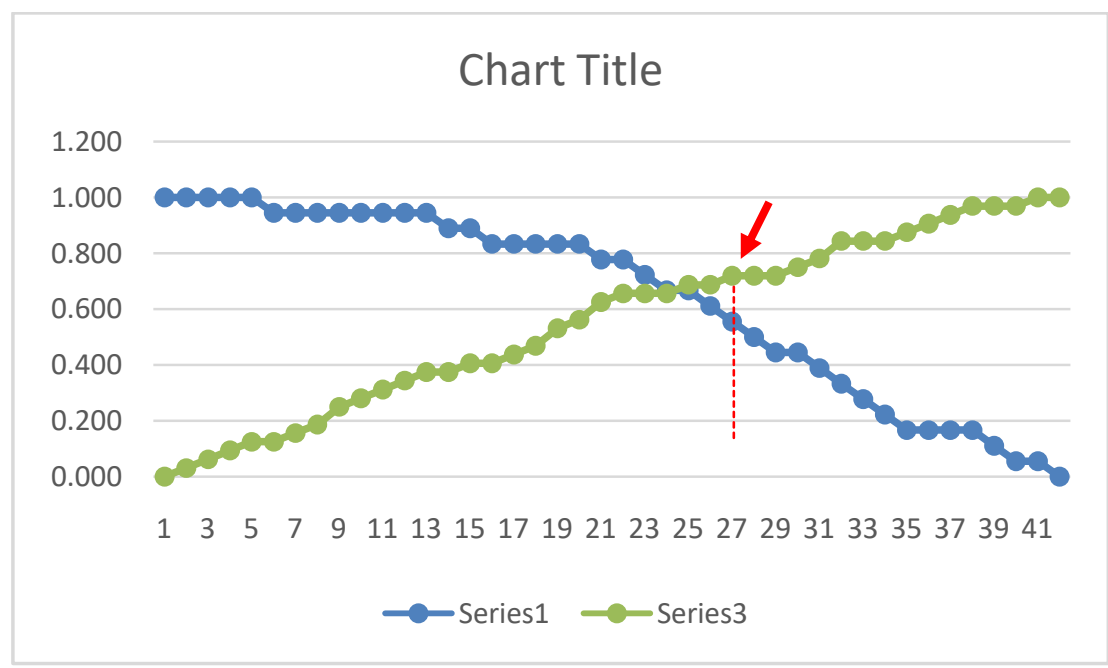

Figure 2. The cutting point of 6 MWT showed GLS $>-13.8 \%$ at 375 meters distance with sensitivity of $72.2 \%$ and specificity of $65.6 \%$

In the previous results, it was found that there was a difference in mean functional capacity of patients after acute myocardial infarction in GLS $>-13.8 \%$ and GLS $\leq-13.8 \%$. The functional capacity was obtained by converting the distance obtained at 6 MWT into VO2max. Mileage is the main component to get an estimated/ estimated VO2max. The cutoff point of 6 MWT indicates a significant infarct area marked with GLS> $-13.8 \%$ and an insignificant infarct area characterized by GLS $\leq-13.8 \%$ is 375 meters. By dividing the group into groups of patients who can reach distances $>375$ meters and <375 meters bivariate analysis of factors that influence the distance of 6 MWT of patients after acute myocardial infarction.

Some variables of bivariate analysis are: gender, age $>60$ years and age $<60$, 
body mass index $>25$ and $<25$, killip I and killip II-IV, anterior IMA type and nonanterior IMA type, ventricular ejection fraction left $<50 \%$ and $>50 \%$, fibrinolytic therapy, success of fibrinolytic therapy and GLS $>-13.8 \%$ and GLS $<-13,8 \%$ (Table 4 ). The time interval of the 6 MWT training test on the infarction onset has the distribution of unheard-of-normal data with the time span of 6 MWT training assays on days 4-9 of the onset of infarction. The timing of the 6 MWT training did not affect the difference in the distance of 6 MWT (Table 5). The IMA infarction type with EST and IMA without EST also did not show an effect on the achievement of 6 MWT distance because the proportion of patients with IMA without EST was smaller than IMA EST.

Table 4. Bivariate analysis of several variables that affect the distance of 6 MWT

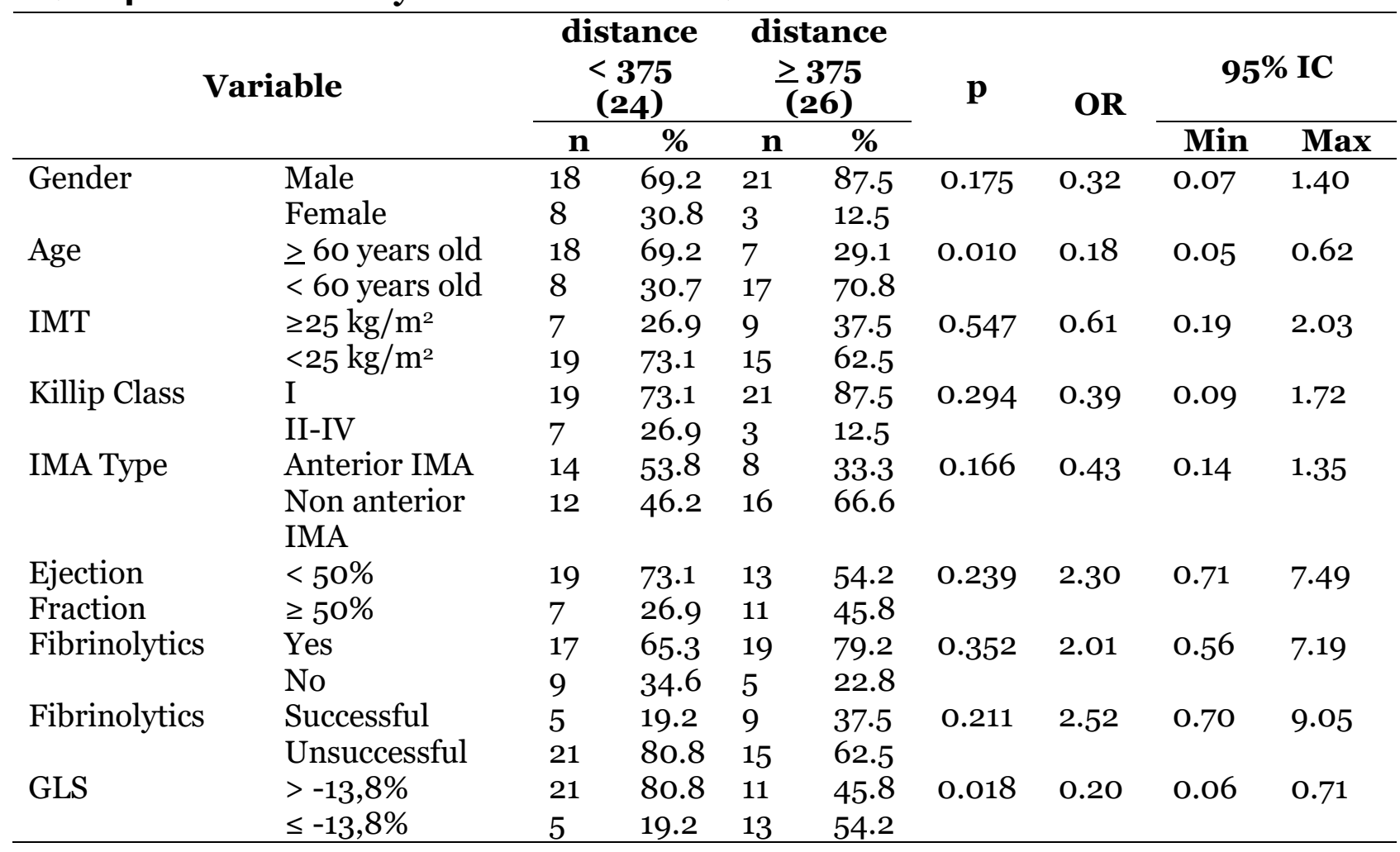

Table 5.The effect of time implementation of 6 MWT on distance achievement of 6 MWT

\begin{tabular}{llcc}
\hline Distance & S & Median (min-max) & p \\
\hline Distance $<375 \mathrm{~m}$ & 26 & $5(4-9)$ & 0.838 \\
Distance $\geq 375 \mathrm{~m}$ & 24 & $5(4-9)$ & \\
\hline
\end{tabular}

Table 6.Multivariate analysis of several variables on 6 MWT distance

\begin{tabular}{llllllll}
\hline & \multirow{2}{*}{ Coefficient } & \multirow{2}{*}{ S.E } & \multirow{2}{*}{ Wald } & \multirow{2}{*}{ p } & \multirow{2}{*}{ OR } & \multicolumn{2}{c}{ 95\% CI } \\
\cline { 6 - 8 } & & & & & & Min. & Max. \\
\hline GLS & 2.08 & 0.80 & 6.77 & 0.009 & 7.97 & 1.67 & 38.03 \\
Mge & 2.39 & 0.82 & 8.56 & 0.003 & 10.90 & 2.20 & 53.97 \\
Male & 1.80 & 1.03 & 3.04 & 0.081 & 6.04 & 0.80 & 45.65 \\
\hline
\end{tabular}


If it was grouped into patients who recievedfibrinolytic and non-fibrinolytic therapy, it was found that the introduction of fibrinolytic therapy did not affect the distance of 6 MWT. However, the success of fibrinolytic therapy has an impact on the achievement of 6 MWT distance. Several other variables affecting a distance of 6 MWT and having $\mathrm{p}<0.25$ of which were age, gender, anterior and non anterior IMA type, ejection fraction and left ventricular of GLS value.

In a multivariate analysis with logistic regression, there was a relationship between 6 MWT and left ventricular GLS and age in patients after acute myocardial infarction (Table 6). While the gender variables indicate that there was no significant relationship. It was based on the Wald test for gender variables and the score was 3.04. The wald test score $<3.84$ for each degrees of freedom with $\mathrm{p}>0.05$ indicated that there was no relationship between the two variables.To assess the relationship between the two variables, it can be indicated by the confidence interval that past one (o.80 to 45.65), therefore, it can be concluded that there was no significant relationship between male gender and the distance of 6 MWT in patients after acute myocardial infarction.

The relationship between 6 MWT distance and left ventricular GLS was statistically significant with an odds score of 7.967 which was the post-infarct patients with non significant infarct area (which has $<-13,8 \%$ GLS) to get the distance of $>375$ meters was 8 times compared to postinfarction patients with significant infarct wide(GLS >-13.8\%). Meaningful significant relationship also showed by 6 MWT distance and age with odds score of 10.898 , who were post-infarct patients $<60$ years old, to get $>375$ meters distance was 10 times compared to post-infarct patients of $>60$ years old.

\section{DISCUSSIONS}

This study was intended to find out the relationship between left ventricular GLS with post-IMA patient functional capacity with EST and IMA without EST as measured by 6 MWT. Patients were divided into left ventricular GLS group <-13.8\% which represented a group with non significant infarct area and left ventricular GLS>-13.8\% as a group with significant infarct wide. The significant infarct area characterized by an area of infarct $>12 \%$ if measured with LGE-MRI and has a sensitivity of $85 \%$ and $96 \%$ specificity if it was assessed by $>-13.8 \%$ GLS (Loutfi et al., 2010). Patients with significant infarct wide had 2 years death prognosis of $7 \%$ compared to $\mathrm{o} \%$ for patients with non significant infarct area.

The distance that can be taken by the patient after myocardial infarction with <$13.8 \%$ GLS farther than $>-13.8 \%$ GLS $(392.39+49.44 \mathrm{~m}$ and $347.97+65.49 \mathrm{~m} ; \mathrm{p}=$ o.016). From the various formulas to estimate VO2max from 6 MWT, distance was the most powerful variable in estimating VO2max. Valeur et al., (2005) assessed the importance of pre-discharge training in post-infarct patients who did the reperfusion therapy with fibrinolysis as well as with primary percutaneous coronary intervention(PPCI) that the functional capacity was a strong predictor of the occurrence of mortality and recurrent infarction without therapy strategies. The mortality after 3 months was more common in the groups who were unable to perform exercise test compared to those who were able to do exercise test $(6.1 \%$ and $40 \%$; $<<0.001$ ). 
From the result of this study, it can be concluded that there was a difference in functional capacity measured by VO2max in both groups.A group of $<-13,8 \%$ GLS has better functional capacity with VO2max $11.04 \pm 0.98 \mathrm{ml} / \mathrm{kgBB} / \mathrm{min}$ compared to $>-$ $13.8 \%$ GLS groupwith VO2max $10.17 \pm 1.3$ $\mathrm{ml} / \mathrm{kgBB} / \mathrm{min} ; \mathrm{p}=0.018$. Post-IMA patients with low functional capacity have lower life expectancy compared to patients without coronary heart disease. In the ACC/AHA guidelines, the practice test in post-IMA patients was used for evaluation of prognosis, prescribing activities, evaluation of therapy, and cardiac rehabilitation. Cardiac rehabilitation programs were useful in reducing mortality from cardiovascular causes by 20\% -25\% (Arena et al., 2007). By knowing the mileage during the training test which reflect the functional capacity of the $<-13.8 \%$ GLS group and $>-$ $13.8 \%$ GLS, it can be estimated that the exercise can be given to post-infarct patients by observing the wide of infarction.

In patients with a wider infarct group which was $>-13.8 \%$ GLS, had an older mean age which was 576 years old compared to $\leq-$ $13.8 \%$ GLS, age 55 years, however, there was no significant difference. In the group with $>-13.8 \%$ GLS, it can be seen that there was an anterior IMA type group with a higher proportion compared to the group with $\leq-13.8 \%$ GLS (56\% and 22\%) with p $<0.05$. Left ventricular ejection fraction in patients with $>-13.8 \%$ GLS had lower scores (43\% and 52\%) with $\mathrm{p}<0.05$. This was in line with Minicucci et al., (2014) who investigated the effect of IMA patients teraphy on the recovery of post-IMA ventricular function, which showed that patients with systolic dysfunction characterized by left ventricular ejection fraction $<50 \%$ had a larger infarct area than patients without systolic dysfunction. Despite aggressive therapy, this systolic dysfunction occured more frequently in patients with anterior IMA type.

A study by Dutcher et al., (2007) evaluated exercise capacity and left ventricular ejection fraction as a predictor of long-term mortality of IMA EST patients treated withPPCI, it was found that exercise capacity < 4 METs as a significant predictor of 5 years mortality rate with $4,54 \mathrm{OR}$. In contrast to the current study, this study used a 6-week post-IMA symptom-limited ergometry and current research with 6 MWT and was performed on day 4-9.The time difference between the practice test and the post-infarction condition of the myocardial infarction (still viable), explained the difference of functional capacity results.

\section{Factors Affecting Functional Capacity and 6 MWT Distance in Acute Myocardial Infarction Patients}

To find out the number of distance point that the patient can travel with $>-13.8 \%$ GLS, the ROC curve obtained the distance by 375 meters.The patients were divided into groups based on the cut-off point that can be reached in the 6 MWT training test, which was <375 meters and >375 meters group.Bivariate analysis of several factors affecting the 6 MWT distance were gender, age, anterior IMA type, left ventricular ejection fraction, successful fibrinolytic therapy, and left ventricular GLS.

Until now, there has been no study showing a distance of 6 MWT of post-IMA patients who divide the infarct wide of $>12 \%$. Research on IMA patients receiving fibrinolysis therapy and performed $6 \mathrm{MWT}$ and linked it to a 3-months prognosis post IMA was done by Hassan et al., (2014), who stated that patients who travel $<300$ meters and having a high GRACE score were 4 times more likely to experience major cardiovascular incident. The median 
distance of 6 MWT in the population was 270 meters (162-462 meters) with the average group distance I ( $>450$ meters), group II (300-450 meters) and group III (<300 meters) respectively 466 meters, 352 meters and 106 meters.Another study in post-IMA patients with cardiac rehabilitation programs assessing the difference in the 6 MWT distance which showed clinical improvement assessed by patient perceptions by 25 meters (Gremeaux et al., 2011). Because 6 MWT was widely accepted as a tool for assessing pharmacologic therapy response and rehabilitation and the mileage during the training test became an important prognostic factor, the reference score can be used as a basis for post-IMA rehabilitation. Another advantage of 6 MWT were practical, safe, low cost, and can be applied in everyday activities (Arena et al., 2007).

If it was compared to the division of groups based on the cutoff point that can be reached in the $6 \mathrm{MWT}$ training test, which were <375 meters distance and >375 meters group, it can be seen that $>60$ years old patients have lower mileage (Table 4). Functional capacity was not based entirely as a result of cardiac function but also as part of the accompanying morbidity. The inability to perform the training test was a feature of low functional capacity and a negative predictor in post-IMA patients. Those groups of patient had older age characteristics, more in women, had previous infarction, and had extensive coronary artery disease (Borjesson and Dellborg, 2005).

Training capacity was affected by age and there was a decrease of $8-10 \%$ per decade. The decreases were due to decreased stroke volume, maximum heart rate, blood flow to skeletal muscle, and skeletal muscle function (Arena et al., 2007). A study which involved the normal population connecting the mileage at 6 MWT with age found that there was a difference of 6 MWT distance between the age group of 20-40 years old, 40-60 years old and $>60$ years old, which were $645.19 \pm$ $80.78 \mathrm{~m} ; 540.68 \pm 59.74 \mathrm{~m}$ and $457.39 \pm$ $64.1 \mathrm{~m}$ (Pires et al., 2007).

In bivariate analysis, it was found that female gender had an effect on functional capacity. VO2 max in male was $10-20 \%$ higher than female. This was partly due to hemoglobin levels, a higher proportion of muscle mass, and stroke volume (Arena et al., 2007).The difference in VO2max which represented by achievement of 6 MWT by gender was also in line with Crapo et al., (2002) who indicated that a distance of 6 MWT was found in a healthy adult population, the distance median of 6 MWT was $580 \mathrm{~m}$ for males and 500 for females.

In this study, from 36 patients who received fibrinolysis, 14 of them were included in the success criteria of fibrinolysis (39\%). The proportion of patients who met the criteria for successful fibrinolysis was greater in the $>375$-meter group, compared to $<375$ meters ( $47 \%$ and $29 \%$ ). A study conducted by Ndrepepa et al., (2005) assessed the association between residual blood flow and ventricular function recovery, it was found that there were significant differences in perfusion defects but there was no difference in the number of hypochynetic areas. The incompatibility of perfusion and contraction indicated that the occasional infarct related artery (IRA) association played a role in maintaining the perfusion to most areas at risk and becoming a stunning myocardium. Stunning myocardium improved the regional motion function of time-dependent ventricular wall. In GLS measurements, within 48 hours of infarction onset, myocardial ischemia and contractile degradation would be recorded as dysfunctional areas due to 
ischemic conditions in the myocardium disrupting the contractile function. The dysfunction may persist for several hours in myocardial ischaemia but it did not cause the myocardium to become an infarct and would return to normal function (Camici et al., 2008). In the early stages of this infarction, left ventricular GLS cannot distinguish myocardial inflammation due to infarction or impaired motion due to stark myocardium. This was supported by a study done by Dimitriu-Leen et al., (2017), which stated that post-IMA myocardial ischemia affected the left ventricular GLS. Residual ischemia was associated with lower left ventricular GLS.This explained why the bivariate analysis of fibrinolyticefficacy affected 6 MWT distance in post-myocardial infarction patients, but has no effect on multivariate analysis.

In bivariate analysis, if it was divided into anterior and non-anterior IMA group, 6 MWT distance was affected by anterior IMA type with $\mathrm{p}=0.166$, however, there was no meaningful relationship on multivariate analysis. Patients with the anterior IMA type were more likely to experience systolic dysfunction as indicated by a lower left ventricular ejection fraction and the IRA in LAD was an independent predictor on the magnitude of the early infarction perfusion defects (Ndrepepa et al., 2005).

Left ventricular ejection fraction affected the functional capacity in bivariate analysis, but it was not proven in multivariate analysis.Arena et al, (2007) also stated thatthe degree of damage/ disturbance in the myocardium has an effect on the functional capacity. Another influential factor was a 3-week total rest which would decrease the functional capacity by $25 \%$ and heredity.

In accordance with multivariate analysis results, the left ventricular GLS affected the functional capacity as mea- sured by 6 MWT. This showed the deformation of longitudinal myocardial fibers affected by myocardial ischemia/ infarction characterized by lower left ventricular GLS (>-13.8\% GLS). GLS was superior in the assessment of systolic function compared to left ventricular ejection fraction. Left ventricular GLS can detect a decrease in systolic function in patients with heart failure with systolic function maintained with a decrease in exercise capacity (Hasselberg et al., 2013). In the long-term stratification risk of post-IMA patients, Antoni et al., (2010) showed that left ventricular GLS was higher than left ventricular ejection fraction, >-15.1\% GLS had a hazard ratio of 4.5 (95\% CI= 2.1 to 9.7) to all-cause mortality.

In this study, GLS measurements were taken in 48 hours of onset of myocardial infarction and 6 MWT of training was performed at 4 to 9 days hospitalization range with a median of day 5 .The timing of this training test has no effect on the achievement of 6 MWT distance (Table 5). In groups recieving fibrinolysis and successful fibrinolysis, they would have benefit from preservation of myocardial blood flow by saving at risk area from developing into infarct tissue and/or becoming a stunning myocardy.

Functional capacity was also associated with the disease or treatment that may affect its components. $\beta$-blocker therapy in acute situations modified the muscular metabolic system and reduced resistance to exercise capacity as indicated by increased tired perception during exercise, lower VO2max and lower exercise heart rate. A study byWesthoff et al., (2007)showed that the effect of $\beta$-blocker therapy in hypertensive patients did not interfere the benefits of exercise, although it was found that maximal heart rate during exercise was lower. In this study, there were 
9 patients with an inferior IMA diagnosis and 1 anterior IMA patient with a highdegree AV block history who did not receive $\beta$-blockers. This study did not distinguish the groups of patients with $\beta$-blocker and without $\beta$-blocker therapy. Under these conditions, it was expected that this study may include different clinical conditions in post-IMA patients.

\begin{tabular}{l}
\hline REFERENCES \\
\hline Antoni ML, Mollema SA, Delgado V, et al. \\
(2010). Prognostic Importance of \\
Strain and Strain Rate after Acute \\
Myocardial Infarction. Eur Heart \\
Jour; 31: 1640-1647
\end{tabular}

Arena R, Myers J, Williams MA, et al. (2007). Assessment of Functional Capacity in Clinical and Research Settings. Circulation. 116: 329-343.

Baptista CB, Palhares LC, de Oliveira PPM, et al. (2012). Six-minute Walk Test as a Tool for Assessing the Quality of Life in Patients Undergoing Coronary Artery Bypass Grafting Surgery. Rev Bras Cir Cardiovasc. 27(2):231-239

Borjesson M, Dellborg M (2005). Exercise testing post-MI: still worthwhile in theinterventional era. Eur Heart J: 26; 105-106.

Buckberg G, Hoffman JIE, Mahajan A, et al. 2008. Cardiac mechanics revisited: The relationship of Cardiac Architecture to Ventricular Function. Circulation. 118:2571-2587.

Burke AP, Virmani R (2007). Pathophysiology of Acute Myocardial Infarction. Med Clin N Am 91(4): 553-572.

Camici PG, Prasad SK and Rimoldi OE. 2008. Stunning, Hibernation, and Assessment ofMyocardial Viability. Circulation. 117:103-114.

Crapo RO, Casaburi R, Coates AL, et al. 2002. ATS statement: Guidelines for the Six-minute Walk Test. Am J Respir Crit Care Mes; 166: 111-117

Crossman D.C, 2004. The Pathophysiology of Myocardial Ischaemia. Heart; 90: 576-580

De Bruyne B and Heyndrickx GR. 2007. Changes in Infarct Size and Left Ventricular Ejection Fraction New Prognostic Factors After Acute Myocardial Infarction? J Am CollCardiol: 50(2): 157-158.

Dharma S, Juzar DA, Firdaus I, et al. 2012. Acute myocardial infarction system of care in the third world.Neth Heart $\mathrm{J}$ 20(6): 254-259.

Diao K, Yang Z, Ma M, et al. 2017. The Diagnostic Value of Global Longitudinal Strain (GLS) on Myocardial Infarction Size by Echocardiography: A Systematic Review and Metaanalysis. Scientific report; 7: 1-8

Dimitriu-Leen AC, Scholte AJ, Katsanos S, et al. 2017.Influence of Myocardial Ischemia Extent on Left Ventricular Global Longitudinal Strain in Patients after ST-Segment Elevation Myocardial Infarction. Am J Cardiol; 119: 1-6

Dutcher JR, Kahn J, Grines C, et al. 2007.Comparison of left ventricular ejection fraction and exercise capacity as predictors of two and five-year mortality following acute myocardial Infarction. Am J Cardiol; 99: 436-441

Eek C, Grenne B, Braunvand H, et al. 2010. Strain Echocardiography and Wall Motion Score Index Predicts Final Infarct Size in Patients with Non-STSegment-Elevation Myocardial Infarction. Circ Cardiovasc Imaging; 3: 187-194

Ekanayaka R and Waniganayake Y. 2013. Value of the 6 Minute Walk Test in Predicting Multi Vessel Coronary Arterial Disease. Open Journal of Internal Medicine; 3: 42-49. 
Ersball MD. 2013. Left Ventricular Global Longitudinal Strain in Acute Myocardial Infarction. Dan Med J; 6o(8): B4697

Fazlinejad A, Samadzade A, Bagheri R.K, et al. 2016. Does Global Longitudinal Speckle-tracking Strain Predict Left Ventricular Remodeling in Patients with Myocardial Infarction? a Systematic review.RevClin Med; 3: 53-58

Ferreira PA, Ferreira PP, Batista AKM, et al. 2015. Safety of the six-minute Walk Test in Hospitalized Cardiac Patients.Int J CardiovascSci; 1(1): 7077.

Folta A, Metzger BL (1989). Exercise and Functional Capacity After Myocardial Infarction. Journal of nursing scholarship; 21(4): 215-219

Gerson C Jr, Bernadelli GF, Arena R, et al. 2010. Cardio-Respiratory Responses of the Six Minute Walk test in Patients with Refractory Heart Failure during the Preoperative Period for Heart Transplant Surgery. Monaldi Arch Chest Dis; 74(2): 64-69

Gjesdal O, Hopp E, Vartdal T, et al. 2007. Global Longitudinal Strain Measured by Two-Dimensional Speckle Tracking Echocardiography is Closely Related to Myocardial Infarct Size in Chronic Ischaemic Heart Disease. Clinical science. 113:287-296

Gjesdal O, Helle-Valle T, Hopp E, et al. 2008. Noninvasive Separation of Large, Medium, and Small Myocardial Infarcts in Survivors of Reperfused ST-elevation Myocardial Infarction: A Comprehensive Tissue Dopler and Speckle-Tracking Echocardiography Study. CircCardiovasc Imaging;1: 189196

Gremeaux V, Troisgros O, Benaim S, et al. 2011. Determining the Minimal Clinically Important Difference for the six-
Minute Walk Test and the 200-Meter Fast-Walk Test during Cardiac Rehabilitation Program in Coronary Artery Disease Patients After Acute Coronary Syndrome. Arch Phys Med Rehabil; 92: 611-619

Hassan AKM, Dimitry SR and Agban GW. 2014. Can Exercise Capacity Assessed by the 6 Minute WalkTest Predict the Development of Major Adverse Cardiac Events in Patients with STEMI after Fibrinolysis?PLoS ONE 9(6): e99035. doi:10.1371/journal.pone.oo99035

Hasselberg NE, Haugaa KH, Sarvari SI, et al. 2014. Left ventricular global longitudinal strain isassociated with exercise capacity in failing heartswith preserved and reduced ejection fraction. Eur Heart $\mathrm{J}$ - Cardiovascular Imaging. 16: 217-224.

Holmes JW, Borg TK, Covell JW. 2005. Structure and Mechanics of Healing Myocardial Infarcts. Annu Rev Biomed Eng;7:223-253

Iacoviello M, Puzzovivo A, Guida P, et al. 2013. Independent Role of Left Ventricular Global Longitudinal Strain in Predicting Prognosis of Chronic Heart Failure Patients. Echocardiography; 30: 803-811.

Irmalita, Juzar DA, Andrianto, et al. 2015. PedomanTatalaksanaSindromKorone rAkut. http: //jki.or.id.

Jneid H. 2016. Cardiac Rehabilitation After Myocardial InfarctionUnmet Needs and Future Directions. Article Information JAMACardiol; 1(9): 978-979

Kalam K, Otahal P and Marwick TH. 2014. Prognostic Implications of Global LV Dysfunction: a systematic review and meta-analysis of global longitudinal strain and ejection fraction. Heart; 0 : 1-8. 
Kearney LG, Lu K, Ord M, et al. 2012. Global Longitudinal Strain is a Strong Independent Predictor of All-cause Mortality in Patients with Aortic Stenosis. Eur Heart J Cardiovasc Imaging. 13:827-833

Kumler T, Gislason GH, Kober L, et al. 2010. Persistence of the Prognostic Importance of Left Ventricular Systolic Function and Heart Failure after Myocardial Infarction: 17-year followup of the trace register. European journal of heart failure;12:805-811

Loutfi M, Ashour S, El-Sharkawy E, et al. 2010.Identification of High-Risk Patients with Non-ST Segment Elevation Myocardial Infarction using Strain Doppler Echocardiography: Correlation with Cardiac Magnetic Resonance Imaging. Clin Med insights Cardiol; 10: 51-59

Minicucci MF, Farah E, Fusco DR, et al. 2014. Infarct Size as Predictor of Systolic Functional Recovery after Myocardial Infarction.Bras Cardiol.

Munk K, Andersen NH, Nielsen SS, et al. 2011.Global Longitudinal Strain by Speckle Tracking for Infarct Size Estimation. Eur J Echocardiogr; 12: 156-165

Nogueira P.A, Leal A.C.M, Nogueira E.D.B, et al. 2006. Clinical Reliability of the 6 Minute Corridor Walk Test Performed Wiyhin a Week of a Myocardial Infarction. Int Heart $\mathrm{J} ; 47$ : 533-540.

Ndrepepa G, Kastrati A, Schwaiger M, et al. 2005. Relationship Between Residual Blood Flowin the Infarct-Related Artery and ScintigraphicInfarct Size, Myocardial Salvage, and Functional Recovery in Patients with Acute Myocardial Infarction. J Nucl Med; 46:1782-1788
Pires SR, Oliveira AC, Parreira VF, et al. 2007. Six Minutes Walk Test at Different Ages and Body Mass Indexes. Rev bras fisioter: 22(2): 131134

Pollentier B, Irons SL, Benedetto CM, et al. 2010. Examination of the Six Minute Walk Test to Determine Functional Capacity in People with Chronic Heart Failure: a systematic review. Cardiopulm Phys Ther J; 21:13-21

Reed GW, Rossi JE and Cannon CP. 2016. Acute myocardial infarction. Lancet 389(10065): 197-210

Rosendahl L. 2010. Infarct Size and MyocardialFunction.Faculty of Health Science, Linköping University Dissertation, No. 1169. http://www.liu.se/cmr.

Stanton T, Leano R and Marwick TH. 2009. Prediction of All-cause Mortality from Global Longitudinal Speckle Strain: Comparison with Ejection Fraction and Wall Motion Scoring. CircCardiovasc Imaging; 2: 356-364

Scirica BM and Morrow DA. 2015. STElevation Myocardial Infarction: Pathology, Pathophysiology, and Clinical Features. 10th ed. In: Mann DL, Zipes DP, Libby P, et al. (eds), Braunwald's Heart Disease A Textbook of Cardiovascular Medicine, Philadelphia: Elsevier, pp. 1068-1083 Swain DP, Brawner CA, Chambliss H O, et al. 2014. ACSM's Resources Manual for Guidelines for Exercise Testing and Prescription. 7th edition.Wolter Kluwer. Philadelphia

Thygesen K, Alpert JS, Jaffe AS, et al. 2012. Third universal definition of myocardial infarction.Eur Heart J 33(20): 2551-2567.

Valeur N, Clemmensen P, Saunamaki K, et al. 2005. The prognostic value of predischarge exercise testing after 
myocardial infarction treated with either primary PCI or fibrinolysis: a DANAMI-2 substudy. Eur Heart J. 26: $119-127$.

Venkatesh N, Thanikachalam S, Murthy S, et al. 2011. Six Minute Walk Test: a Literary Review. SRJM; 4: 30-34.

WesthoffTh, Franke N, Schmidt S, et al. 2007. Beta-blockers do not Impair the
Cardiovascular Benefits of Endurance Training in Hypertensives. Journal of human Hypertension: 21; 486-493. Yingchoncharoen T, Agarwal S, Popovi ZB, et al. 2013. Normal Ranges of Left Ventricular Strain: A Meta-Analysis. J Am SocEchocardiogr; 26: 185-191. 